\title{
Types of Help Provided by Caregivers Following a Stroke: Optimizing Participation in Daily Activities and Social Roles According to Cognitive Deficits
}

\author{
Chantal Viscogliosi*, Chantal Caron ${ }^{2}$, Johanne Desrosiers $^{3}$ and Sylvie Belleville 4 \\ ${ }^{1}$ Faculty of Arts and Humanities, University of Sherbrooke, 2500 University Boulevard, Sherbrooke, Québec, Canada \\ ${ }^{2}$ Faculty of Medicine and Health Sciences, School of Nursing, University of Sherbrooke, 300112 th Avenue, Sherbrooke, Québec, Canada \\ ${ }^{3}$ Faculty of Medicine and Health Sciences, School of Rehabilitation, University of Sherbrooke, 3001 12th Avenue, Sherbrooke, Québec, Canada \\ ${ }^{4}$ Department of Psychology, University of Montreal, Montreal, Quebec, Canada
}

\begin{abstract}
Objectives: This study aimed 1) to explore the types of help provided by caregivers to optimize the level of participation in daily activities and social roles of older adults with cognitive deficits following a stroke, and 2) identify
\end{abstract} contextual factors that influence their choice.

Design: A descriptive qualitative design was used.

Subjects/Patients: Twelve family caregivers participated in the study.

Methods: Each caregiver was interviewed three times: one month, three months and six months following the care receiver's discharge to the community after receiving services from an acute care hospital, rehabilitation unit or geriatric day hospital. Their care receiver had previously taken a battery of cognitive tests and answered a questionnaire on participation for another part of the study. Qualitative data were analyzed using the approach of Miles and Huberman.

Results: Caregivers' types of help varied according to factors related to their own and the care receivers' characteristics, their relationship and the environment. Caregivers provided various types of help including cognitive support, stimulation, supervision, teaching, repair, emotional support, physical assistance, situation avoidance, substitution and voluntary non-intervention. Some of these types of help are more appropriate to promote participation.

Conclusion: Understanding the context of help could enable professionals to partner better with caregivers to promote care receivers' participation in daily activities and social roles.

Keywords: Aging; Caregivers; Mental processes; Activities of daily living; Qualitative; Stroke

\section{Introduction}

Physical, cognitive, emotional and social disabilities often occur following a stroke. In $25-50 \%$ of persons who had a stroke, these disabilities are severe enough to require help in Activities of Daily Living (ADL) [1]. The cognitive deficits that frequently result from a stroke are particularly problematic and impede participation, even after adjusting for physical disabilities [2]. In the Disability Creation Process (DCP) model [3], the concept of participation refers to people's involvement in their daily life activities (nutrition, fitness, personal care, housing, mobility, and communication) and social roles (responsibilities, interpersonal relationships, community life, employment, education, leisure). Thus participation encompasses a wide variety of social roles [3]. According to the DCP model (Figure 1), physical and social environmental factors interact with personal factors as facilitators or obstacles to participation.

Caregivers are part of the social environmental factors and their presence and role might have a significant impact on the care receiver's participation [3]. In particular, the help provided by caregivers might influence the level of participation [3]. Studies have shown that functional gains after a stroke [4] and participation six to 12 months after returning home [2] are influenced by the help provided by caregivers. In fact, when caregivers focus on promoting independence in activities, care receivers are more independent in ADL [4]. According to Bhogal et al. [4], providing the minimum amount of assistance needed according to the magnitude of the disabilities in ADL and Instrumental activities of daily living (IADL), in addition to a high level of emotional support, was the most beneficial combination to promote independence in activities (Figure 2).
However, even if caregivers' help is often essential to enable people who had a stroke to remain in the community, Guberman et al. [5] have criticized the fact that most health professionals perceive caregivers as quasi-professionals aiming to compensate for deficits and providing nursing care. This conception might underestimate intangible aspects of help such as psychological support. In addition to this restrictive vision of the help provided, health professionals view caregivers as health care system resources instead of partners with expertise [5]. To better understand the caregivers' role, Bowers [6] studied the help provided in a broader context. In studies based on grounded theory, Bowers described the role of caregivers in taking care of the care receiver. She identified five different roles: 1) anticipation of care receiver's needs, 2) prevention of physical or mental deterioration, 3) supervision of care provided by formal or informal services, 4) protection of self-esteem and the dyad's relationship, and 5) instrumental tasks (for example, personal care), which are more technical activities to maintain physical

*Corresponding author: Chantal Viscogliosi, Faculty of Arts and Humanities, University of Sherbrooke, 2500 University Boulevard, Sherbrooke, Quebec, Canada, Tel: 1-819-821-8000(\#65917); Fax: 819821-7712; E-mail: chantal.viscogliosi@usherbrooke.ca

Received January 18, 2013; Accepted January 30, 2013; Published February 01,2013

Citation: Viscogliosi C, Caron C, Desrosiers J, Belleville S (2013) Types of Help Provided by Caregivers Following a Stroke: Optimizing Participation in Daily Activities and Social Roles According to Cognitive Deficits. J Gerontol Geriat Res 2: 118. doi:10.4172/2167-7182.1000118

Copyright: (๑) 2013 Viscogliosi C, et al.. This is an open-access article distributed under the terms of the Creative Commons Attribution License, which permits unrestricted use, distribution, and reproduction in any medium, provided the original author and source are credited. 


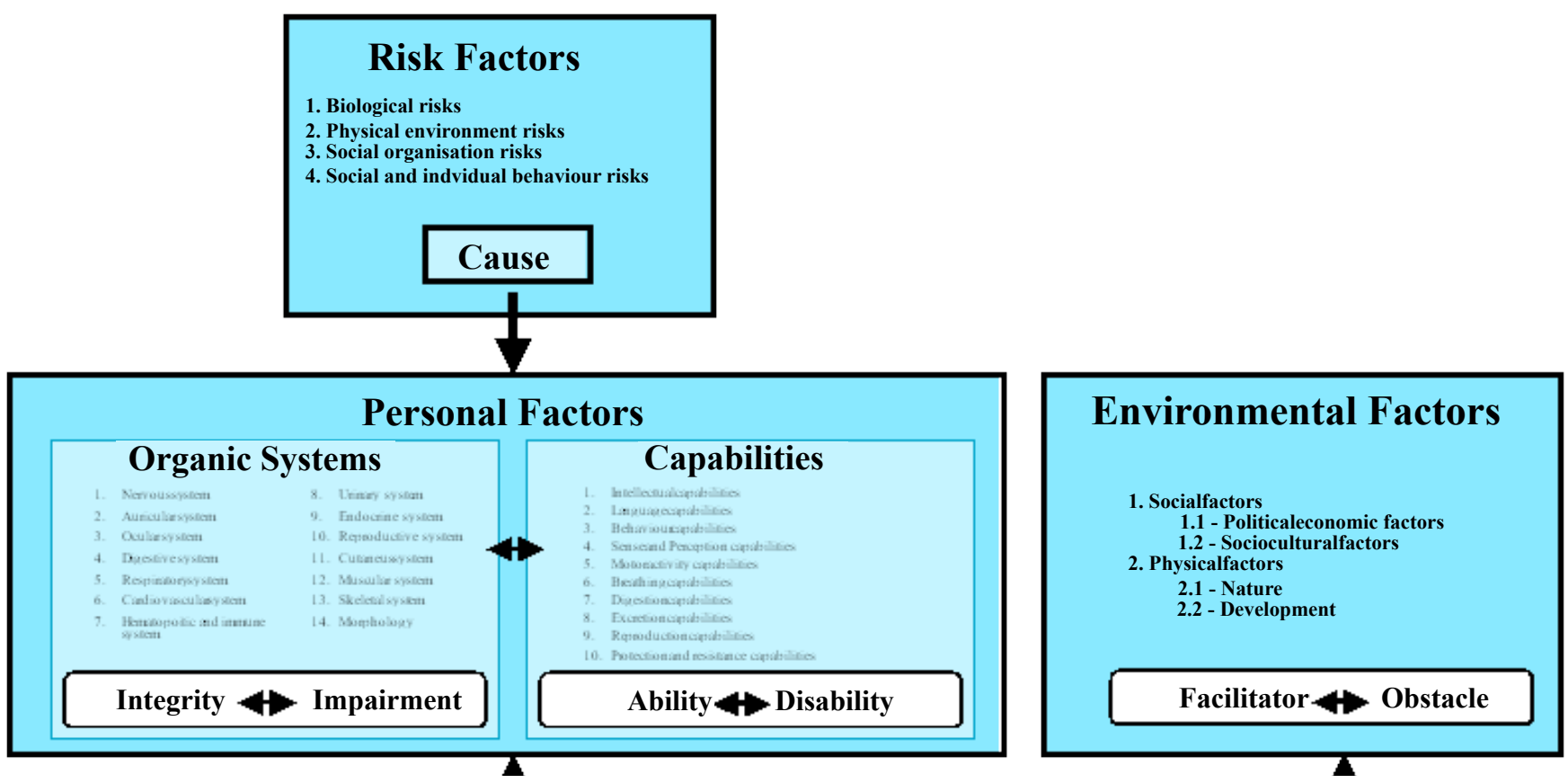

Figure 1: Disability creation process (DCP).

integrity. These tasks require biographical knowledge of the carereceiver's interests, habits and values and sometimes also technical expertise. Vezina and Pelletier [7] identified different types of help provided in dementia such as: "Accomplish", "Delegate", "Control", "Protect", "Prevent", "Stimulate", "Situation avoidance", "Decide or do for the care-receiver" and "Visit" (Figure 2). These types of help were also influenced by the caregiver's characteristics such as own life context, identity, roles and career [7]. Thus it is critical to examine the types of help provided by caregivers because they can vary as a function of the personal and social characteristics of the caregiver and care receiver. One other important factor to take into account is the relationship between the type of help provided and the type of cognitive symptoms experienced following the stroke. Depending on its location, the lesion will affect different cognitive functions, which will have different impacts on activities and how the caregiver perceives the person's needs. It is thus important to explore the elements of the care context.

To our knowledge, no previous study aimed to understand the type of help provided by family caregivers to optimize the participation of older adults according to specific cognitive deficits following a stroke. It is also important to investigate caregivers' rationale for providing a particular type of help. This study aimed to explore the types of help provided by caregivers to optimize the level of participation in daily activities and social roles of older adults with cognitive deficits following a stroke, and to identify contextual factors that influence their choice.

\section{Materials and Methods}

To understand the help provided by caregivers to optimize participation, a descriptive qualitative design was used. Although it was not our aim to explore changes over time in the types of help provided in the first six months after discharge home, conducting three interviews with each caregiver helped deepen our understanding of the help provided in the different participation domains.

\section{Subjects/Population}

Participants in the study were the main caregivers of persons aged 65 years or older who had a stroke. To select caregivers according to a maximum variation sampling method, we reviewed the quantitative files, including cognitive data, of 197 people with stroke who had participated in another part of the study [8]. The cognitive tests, administered at the care receivers' home after discharge from rehabilitation or an acute care hospital, measured deficits in memory, visual perception, executive functions, unilateral attention and language (Table 1) [8]. A sample of caregivers was selected to obtain a variety of type and severity of cognitive deficits among the care receivers, living situation, community care services used by the dyad and the type of dyad's relationship [7,9]. According to the iterative process, saturation was obtained after recruiting twelve caregivers.

Care receivers were approached during their hospitalization to ask their permission to contact their main caregiver. When consent was obtained from care receivers, caregivers were contacted by phone to explain the aims of the study and obtain their consent to participate in qualitative interviews. Every caregiver asked to participate agreed to do so. The study was approved by the Research Ethics Committees and professional services directors of the institutions where care receivers were recruited. Written informed consent was provided by all the care receivers and caregivers.

\section{Data collection}

Semi-structured interviews with caregivers were conducted at their home and lasted approximately 60 to 90 minutes. Each caregiver was interviewed three times: one month, three months and six months following the care receiver's discharge to the community after receiving services from an acute care hospital, rehabilitation unit or geriatric day hospital. The three-month intervals between interviews allowed the caregiver to adapt his/her help to changes in the care receiver's situation. Interviews were conducted by the first author and were recorded and transcribed. Miles and Huberman's [10] approach follows an iterative 


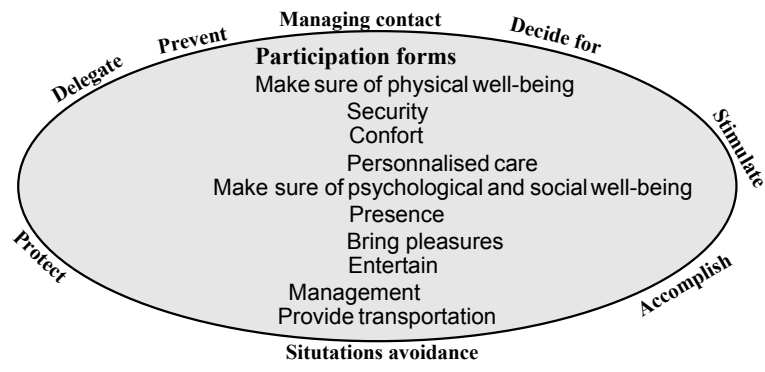

Figure 2: Participation forms and action modalities (Vezina and Pelletier [7]).

Table 1: Quantitative instruments used to determine presence/absence of cognitive deficits in care receivers.

\begin{tabular}{|l|l|}
\hline Cognitive deficits & Instruments \\
\hline Memory deficit & Logical Memory subtest of the WMS III (18) \\
\hline Executive function deficit & Victoria Stroop Test (19) \\
\hline Perceptual deficit & $\begin{array}{l}\text { Motor Free Visual Perceptual Test - vertical version } \\
\text { (MVPT-V) (20) }\end{array}$ \\
\hline Unilateral neglect & Bells Test (21) \\
\hline Language deficits & $\begin{array}{l}\text { Boston Naming Test (BNT) (22) } \\
\text { Token Test - short form (comprehension) (23) } \\
\text { Montreal-Toulouse reading test (24) }\end{array}$ \\
\hline
\end{tabular}

process in the three main steps of the study: sampling, data collection, and analysis. Before data collection, the principal researcher's preconceptions were written down and discussed with co-researchers to be aware of their potential future influence in the interviews and analysis.

A socio demographic questionnaire was administered to caregivers and care receivers to collect information about other factors potentially related to the help provided, such as cohabiting or formal services used by the dyad, gender, age, living arrangements, community services used and relationship between caregiver and care receiver.

\section{Qualitative interview guide}

The qualitative interview guide was developed according to the conceptual framework including 1) the DCP model, 2) Bowers' model, and 3) Vezina and Pelletier's model. It was validated with health professionals and co-researchers with expertise in the field and pretested with one caregiver. After validation, some minor modifications were made to the wording of some questions. The interview began with a very broad question: "We know that stroke has an impact on many activities such as dressing, responsibilities, mobility and leisure. I would like to know how you help X in his/her daily life following his/her stroke." For each caregiver, more in-depth questions followed and were developed based on the care receiver's answers on the participation questionnaire and the data regarding cognitive deficits previously assessed in another part of the study [8]. Each activity performed with difficulty or with help from others was reviewed in the qualitative interview if not mentioned spontaneously. Based on the contextual elements described in Bowers' study [6] on the caregiver's role, the interview guide also covered: 1) participation domains in which help was offered, 2) type of help provided, 3 ) elements related to the caregiver (values, objectives, awareness of cognitive deficits by the caregiver) according to the help given, 4) elements related to the care receiver (personality) in relation to the help given, 5) cognitive deficits perceived by the caregiver, and 6) other external factors that influence the type of help provided. Interviews were constructed to clarify elements only touched upon in the first interviews.
Following are some examples of questions used during the interviews.

- "You told me that when you go to see his doctor, you rephrase the doctor's recommendations; if you didn't do that, what do you think would happen?" "Why do you use this type of help?"

- "What is the most important element that determines the type of help you provide during an activity, for example, taking financial responsibilities?"

- "Could you describe a good thing you did and a mistake you made when helping $\mathrm{X}$ ?”

- "Which factors promote the collaboration of X when you are trying to help him/her?"

Some questions were adapted according to the care receivers' participation and cognitive deficits. For example:

- "What do you do when his/her judgment regarding his/her capacities is altered?"

- "In what circumstances do you emphasize or downplay X's difficulties?"

- "Why do you sometimes prefer not to intervene when you know $\mathrm{X}$ will not be able to do an activity successfully?"

\section{Data analysis}

To describe the sociodemographic and clinical characteristics of the caregivers and care receivers, frequency was used for the categorical variables. To establish the presence of cognitive deficits in people who had a stroke, raw scores were taken for each cognitive test and compared to reference values, as described in more detail [8]. Thus, participants with and without cognitive impairments were identified for each cognitive function.

The research process went back and forth between data collection and analysis to deepen the analysis [10]. The initial coding plan was based on our conceptual framework (participation domains, values, types of help and cognitive deficits reported by caregivers). Qualitative interviews with caregivers were coded and related to cognitive deficits identified in care receivers' files. New themes reported by caregivers were also included in the coding tree. The first author coded all the transcripts. Intercoder reliability of the results was verified at $\mathrm{T} 1$ with part of an interview checked with an external coder. Differences between results were discussed and codes were modified or specified if necessary. Discrepancies were analyzed and the coding tree modified according to this analysis. Coding was done on the different levels related to the themes presented in the interview guide.

The final coding tree covered these themes:

- Types of help

- Life habits

- Characteristics related to the environment

- Dyad's relationship

- Care receiver's characteristics

- Perception of the impact of the type of help provided

- Care receiver's capacities (cognitive, psychological and physical) perceived by the caregiver 
Table 2: Synthesis of the analysis process.

\begin{tabular}{|l|}
\hline Pre-conceptions written down \\
\hline $\begin{array}{l}\text { At each measurement time, for each patient, quantitative tests reviewed to help } \\
\text { develop questions for interviews }\end{array}$ \\
\hline Syntheses written for each interview \\
\hline Interviews transcribed \\
\hline Coding tree developed \\
\hline Interviews coded \\
\hline Methodological memos written (iterative process) \\
\hline Analytical memos written (iterative process) \\
\hline Part of interviews co-coded (intra-judge and inter-judges) \\
\hline Sub-questions prepared for subsequent interviews \\
\hline Intermediate meetings held (3) \\
\hline Characteristics for next recruitment determined \\
\hline Data saturation verified \\
\hline Analysis with matrix \\
\hline
\end{tabular}

Thereafter, coding led to data saturation for each level of coding. Coding was done on NVivo-7@. To meet the objectives of the study, analysis tools of the Miles and Huberman [10] approach were used. A three- to four-page synthesis was written for each caregiver. In the synthesis we noted differences with other interviews with the same caregiver to compare and also generate hypotheses. Methodological memos were written to assure reliability in the process and decisions taken by the research team. Analytical memos helped to suggest hypotheses which were explored with more in-depth questions in later interviews. Researchers' meetings were held to propose themes for more in-depth questions in subsequent interviews. An analytical memo presents hypotheses and also rival hypotheses. To help in constructing hypotheses to be verified in subsequent interviews, matrices were used. In fact, data were displayed in a matrix to compare the type of help provided according to the nature of the cognitive deficits and other factors that had an impact. Table 2 present a synthesis of the analysis process.

\section{Results}

The caregivers encompassed a variety of type and severity of cognitive deficits among the care receivers (memory, executive function, language, perception, and visual attention deficits), living situation, community services used by the dyad and the type of dyad's relationship. Seven of the 12 caregivers who participated in the interviews lived with the care receiver. At the time of the first interview, the care receiver's stroke had occurred on an average of three months earlier. The twelve caregivers were aged 45 to 88 years. Of the care receivers (including four men), seven had memory deficits, eight visual perception deficits, three unilateral neglect, seven executive function deficits in the inhibition component, and seven also presented language deficits. The age of the care receivers varied between 65 and 86, eight lived at home, four in seniors' residences; five of them received community services. The caregivers' relationships with the care receivers included four wives, one husband, a nephew, a step-daughter, a niece, two sisters, one son and a mother. Four caregivers gave 10 or fewer hours of help per week, six gave between 13 and 16 hours, and two gave more than 20 hours of help per week. Caregivers' schooling varied between 0 and 15 years for a median of seven years.

Our results show that the following types of help were used by caregivers to help care receivers: cognitive support, stimulation, supervision, teaching, repair, psychological support, physical assistance, situation avoidance, substitution and non-intervention. Table 3 also shows that types of help vary as a function of the care receiver's specific cognitive deficits following a stroke.

The type of help provided by caregivers following a stroke is also influenced by different characteristics of the caregivers, care receivers, their relationship and the social environment. These characteristics mentioned in the interviews with caregivers are detailed in table 4 , and some are also presented in the transcripts.

\section{Cognitive support}

Cognitive support includes verbal cues, task adaptation and reflection of care receiver's difficulties. Caregivers also provide verbal cues about tasks to be done and memory compensation strategies such as using a diary. Cognitive support is generally the most frequent type of help reported by caregivers in the presence of cognitive deficits following a stroke. This type of help is provided for all participation domains. Even though this type of help is used regardless of the specific cognitive deficit, it is most often used when memory deficits are present. For example, a caregiver reported giving verbal cues by phone to her aunt to help her use the television remote control instead of doing it for her if she lived with her. Moreover, cognitive support is especially used when caregivers are aware of cognitive deficits and do not live with the care receiver. When caregivers use cognitive support, their aim is to promote rehabilitation supported by values of autonomy. They compensate for cognitive deficits and allow the care receiver to do the activity as much as he/she can. This type of help is also provided to enhance safety or maintain control over the environment and the care receiver's well-being in activities, as illustrated by this quote: "When we go to the library, I try to get him to take non-fiction with illustrations because he has difficulty following the story in fiction."

\section{Stimulation}

Stimulation consists in providing verbal support to the care receiver to encourage him/her to initiate or continue activities. This type of help is particularly frequent in the leisure domain, such as for this caregiver who takes care of his aunt's leisure because paid staffs take care of her ADL and IADL. "She does not paint anymore since her stroke. She's a good artist, she paints very well! I said: I'm not paid to help you. I want a painting from you." Stimulation is often reported when the care receiver suffers from executive deficits. This type of help is guided by rehabilitation aims. Stimulation focuses on the values of promoting dignity and autonomy by helping to resume independent activities and also abilities in a stimulating environment.

\section{Supervision}

Supervision takes place when the caregiver makes sure the activity or role is done properly without physical or cognitive help. This type of help is provided as much in daily activity domains as in social role domains. When cognitive deficits accompany physical limitations, caregivers tend to provide more supervision than when the care receiver does not have cognitive deficits. When the care receivers do not have executive deficits, caregivers reduce supervision because they believe they can trust the care receiver to be safe. In contrast, more supervision is provided in the presence of executive and memory deficits, as seen in this quote: "He can't remember. Sometimes he turns on the stove, puts a little oil and onions in a pan and burns them. One time, he put the frypan on the tablecloth, which stuck to it." Caregivers have supervision goals when they oversee activities to help maintain control over the care receiver's environment and safety to allow the care receiver to do activities by him/herself to promote dignity and psychological well-being. 
Table 3: Types of help provided by caregivers to their care receiver in each participation domain according to specific cognitive deficits.

\begin{tabular}{|c|c|c|c|c|c|c|c|c|c|c|}
\hline Domain/Help & Nutrition & Fitness & Personal care & Housing & Mobility & Communication & Responsibilities & $\begin{array}{l}\text { Interpersonal } \\
\text { relationships }\end{array}$ & Community life & Leisure \\
\hline Cognitive support & $E *$ * M & & (E) L M & $E P^{v}$ & $E(H) L M$ & E L M P & E L M & E M & $E(H) L M$ & E L M P \\
\hline Stimulation & & & ${ }^{*} e P$ & $E$ & & $E$ & & $(E)$ & & E L M \\
\hline Supervision & E M & & $E$ & E & ${ }^{*} e \mathrm{~L}$ & $E$ & ${ }^{*} e \mathrm{~L}$ & ${ }^{*} e$ & & E L M \\
\hline Teaching & ${ }^{*} e$ & L & $E$ & E L & & $E$ & E L & & E L & E P \\
\hline Repair & & & $E$ & & $E$ & ${ }^{*} e \mathrm{~L}$ & E L & L & ${ }^{*} e \mathrm{~L}$ & $E$ \\
\hline $\begin{array}{l}\text { Psychological } \\
\text { support }\end{array}$ & & & & $E$ & E L M & L M & & E L M & E L & EP \\
\hline Physical assistance & & & ${ }^{*} e$ & $E$ & E L & & $E$ & & ${ }^{*}$ e M & \\
\hline Situation avoidance & E M & & & E M & E M & $E$ & $E$ & E M & E M & $E P^{\vee}$ \\
\hline Substitution & $(\mathrm{E})(\mathrm{M})$ & $\mathrm{P}$ & L M & $E P^{v}$ & $E$ & $E$ & M & & $E$ & $E L P^{\vee}$ \\
\hline Non- intervention & *e P & $E$ & $E$ & & $(\mathrm{E})$ & M P & E M & LP & E M & E L P \\
\hline
\end{tabular}

*e and *l: type of help used only with care receivers without executive (e) or language (I) deficit

$(\mathrm{X})$ : Deficit perceived by caregivers but not detected by quantitative cognitive tests

$\begin{array}{ll}\text { M: memory deficits } & P \text { : visual perception deficits }\end{array}$

$\mathrm{P}^{\mathrm{v}}$ : probably vision instead of visual perception deficits $\mathrm{E}$ : executive deficits

$\mathrm{L}$ : language deficits $\quad \mathrm{H}$ : unilateral neglect deficits

Table 4: Characteristics that influence the type of help provided by caregivers following a stroke.

\begin{tabular}{|c|c|c|c|}
\hline Factors related to the caregiver & $\begin{array}{l}\text { Factors related to the care } \\
\text { receiver }\end{array}$ & Environment & $\begin{array}{l}\text { Factors related to caregiver/care-receiver } \\
\text { relationship }\end{array}$ \\
\hline $\begin{array}{l}\text { Caregiver's recognition of care receiver's cognitive } \\
\text { deficits } \\
\text { Caregiver's objectives (Anticipation, Protection, } \\
\text { Prevention, Rehabilitation, Supervision) } \\
\text { Caregiver's values (dignity, autonomy, relationship } \\
\text { with others, safety, stimulating environment, } \\
\text { environment control, hope, devotion) } \\
\text { Caregiver's personality } \\
\text { Caregiver's knowledge and experience } \\
\text { Caregiver's limitations }\end{array}$ & $\begin{array}{l}\text { Specific cognitive } \\
\text { deficit } \\
\text { Combination of } \\
\text { cognitive deficits } \\
\text { Care receiver's } \\
\text { personality } \\
\text { Care receiver's } \\
\text { strategies }\end{array}$ & $\begin{array}{l}\text { Help from others } \\
\text { than the caregiver } \\
\text { Reactions from } \\
\text { family and friends } \\
\text { Family } \\
\text { relationship } \\
\text { Community } \\
\text { services utilization }\end{array}$ & $\begin{array}{l}\text { Cohabitation } \\
\text { Concordance of values between } \\
\text { caregiver and care receiver } \\
\text { Deepening of the knowledge of the } \\
\text { care receiver by the caregiver } \\
\text { Quality of the relationship between } \\
\text { caregiver and care receiver }\end{array}$ \\
\hline
\end{tabular}

\section{Teaching}

The caregiver teaches how to do tasks by providing activities and exercises to enhance the care receiver's capacities. This type of help is generally used in domains where safety is not an issue. For example, it is not used in the nutrition domain when the care receiver has memory or executive deficits because caregivers report that this would place the care receiver in a dangerous situation when using the stove. However, for the housing domain, this type of help is used a lot despite executive deficits, as shown in the quote below.

"I want to show her how to use the washing machine. It will probably take more than one try. I should check if she can see the temperature and water level. After doing it together several times, she will probably get it."

This type of help is mostly used with language and executive deficits. When using this type of help, caregivers have rehabilitation aims and want to enhance remaining capacities because they value maintaining autonomy.

\section{Repair}

Repair consists in support or compensation used to correct or restore an action taken by the care receiver. Repair is mostly employed for social roles. However, a caregiver needs to use repair in the presence of executive deficits when the care receiver's executive deficits cause problems in relationships with family members. In fact, this type of help is often used when the care receiver has executive deficits. Repair is also used to compensate for language deficits in comprehension or expression, such as in the case described below.

"She is not able to manage money (language deficits). The hairdresser left me a message and I have to arrange the payment. She had money but she cannot count. Even though she cannot explain to me, in the end I always understand by asking her many questions."

This type of help is sometimes used when safety is an issue and especially for medication when the desire is to maintain physical wellbeing. For example, to prevent a deterioration in her care receiver's condition and ensure her physical well-being, a caregiver preferred to go to her stepmother's home to reorganize her pill dispenser when she phoned and told her that the pharmacy had mixed up the pills. Caregivers also sometimes use repair when they do not understand the care receiver's cognitive deficits.

\section{Psychological support}

Psychological support includes humour, approval, explanation of interventions and downplaying. This type of help is particularly used in interpersonal relationships and leisure domains, especially when stroke causes difficulties in maintaining previous relationships with family and friends. It is also used in the mobility domain, especially when a driving license is taken away. This type of help is provided in the presence of all types of cognitive deficits and more intensively with executive and language deficits, as seen in this quote.

"My sister has difficulty saying her name. I say: You are lucky, you can walk. You could have been paralyzed in a wheelchair; it would have been more difficult. She agrees, I know that she prefers walking than speaking and being in a wheelchair."

It aims to protect the identity of the care receivers in accepting their new limitations and is mostly used to maintain the care receiver's dignity. 


\section{Physical assistance}

Our caregivers seldom provided physical assistance in the care receiver's activities. It was done in a few daily activity domains and only two social role domains. When they used this type of help, it was aimed at reducing the effect of executive deficits. Some caregivers reported providing physical assistance when they saw organizational difficulties (executive functions) experienced by the care receivers. For example, one caregiver provided physical assistance when transferring from a sitting to a standing position in the presence of hemiparesis.

He tried to get up and I said: "Wait, I'm coming. Before I reached him, he fell. I said: Are you able to get up? I held his leg and told him to hold onto the edge of the bed to help him."

This type of help is given by caregivers anticipating the caregivers' needs and helping them maintain control over their environment and dignity.

\section{Situation avoidance}

For situation avoidance, caregivers intervene to limit some activities that they consider hazardous for care receivers. This type of help is used in all social role domains and in four of the six daily activity domains. Situation avoidance is mainly applied with care receivers who present executive deficits. Even though this type of help was not used very much by the caregivers we interviewed, its primary aim is to ensure safety. It is also sometimes inspired by social responsibility; this is often the case with driving.

"When he had his stroke, I asked the doctor to send a report to the government to take away his driving licence because I was afraid in the car when he drives. It is better if the doctor does it because if I tell him he will be angry."

Often, the desire to maintain the quality of the relationship with the care receiver comes first and caregivers agree to set aside some of their own values. In fact, one caregiver said that she preferred to let her aunt manage her money despite her memory and executive deficits rather than damage their relationship. Anticipation of the care receiver's needs impels the caregiver to help maintain the interpersonal relationship. The caregiver especially tries to avoid some situations when not living with the care receiver or having to be absent for a time. For example, in the presence of executive deficits, when the caregiver goes away from home, he limits the use of the stove by the care receiver.

\section{Substitution}

When caregivers do the whole task for care receivers, they use substitution. This type of help takes place in different participation domains. It is mostly used in the presence of memory deficits, as described in this quote regarding medication. "I give him his medication. Before, he used to take it himself but now I don't know if he would remember to take it. He sometimes asks me: Did I take it or not?" To ensure the care receiver's physical well-being especially for safety reasons, some caregivers use this type of help to control the environment. Few caregivers did the activity for the person because it was faster; their focus was more on productivity than autonomy. Substitution is mostly utilized by caregivers who do not understand the reasons for or complexity of cognitive deficits.

\section{Non-intervention}

Occasionally, caregivers voluntarily choose not to help. Nonintervention was seen in 11 of the 12 participation domains. This choice is made by caregivers for any care receiver's cognitive deficits. It aims to prevent deterioration of the care receiver's condition. This approach is common when caregivers want to promote the care receiver's autonomy, as reported by this caregiver: "I don't do anything she didn't ask me to do because it is easier to rely on others. It compels her to do her try to remember. It triggers her memory." It also happens that caregivers do not intervene because they do not understand the cognitive deficits, like one caregiver who mentioned difficulties in nutrition without relating them to the care receiver's perceptual deficits. Caregivers recognizing their own limitations and not living with the care receiver could also contribute to non-intervention. This is the case of a caregiver who does not live with her sister but whom she helps. Sometimes, the non-intervention could have adverse effects, as seen in the case of one caregiver who, despite her desire to maintain her sister's autonomy and well-being, does not intervene to promote leisure because she does not live with her.

\section{Contextual factors influencing the types of help provided by caregivers}

As shown in table 3, the same types of help are used for both daily activity and social role domains. However, a wider variety of types of help is provided for social roles. Moreover, some types of help such as cognitive support are used for almost every domain whereas other types of help such as psychological support focus on specific participation domains. For example, the mobility and housing domains often need psychological support, especially when someone loses their driver's licence or needs to leave her home to go into a more supervised residential setting. Little help is provided by caregivers in the fitness domain aimed at enhancing physical and mental health through exercise. Furthermore, the context of utilization of different types of help differs according to the nature of the cognitive deficits. As shown in table 3, caregivers report providing more help for memory and executive deficits.

Maintaining an optimal relationship with the care receiver was the most important factor that influenced the type of help provided by caregivers. For example, even if a caregiver wants to promote autonomy and use teaching as a type of help, she/he will change the type of help provided if the care receiver reacts negatively. Hence, in addition to the cognitive deficits present, care receivers' reactions also influence the type of help provided by caregivers. Among different characteristics presented in table 4 that influence the help provided, the social environment influences the type of help and also the domains in which caregivers give help. For instance, when the care receiver gets other support, the caregiver has more time to help in social roles such as leisure and not be preoccupied only by survival needs such as those in daily activity domains. Finally, our results showed that the help provided is not only aimed at optimizing participation but also enhancing personal factors such as capacities or reducing obstacles in the environment. This explains why, in figure 3, we decided to place types of help, values and aims in the interaction circle of the original DCP model [3]. As mentioned earlier, values that influence the type of help include maintaining dignity, promoting physical well-being, securing psychological and social well-being, maintaining a stimulating and enriching environment, maintaining relationships with others and fostering autonomy (Figure 3). In addition, our results could be helpful for a deeper understanding of participation. In fact, for each activity and role, a more precise description of human assistance is provided and helps shed light on the relationship between deficits and participation. 


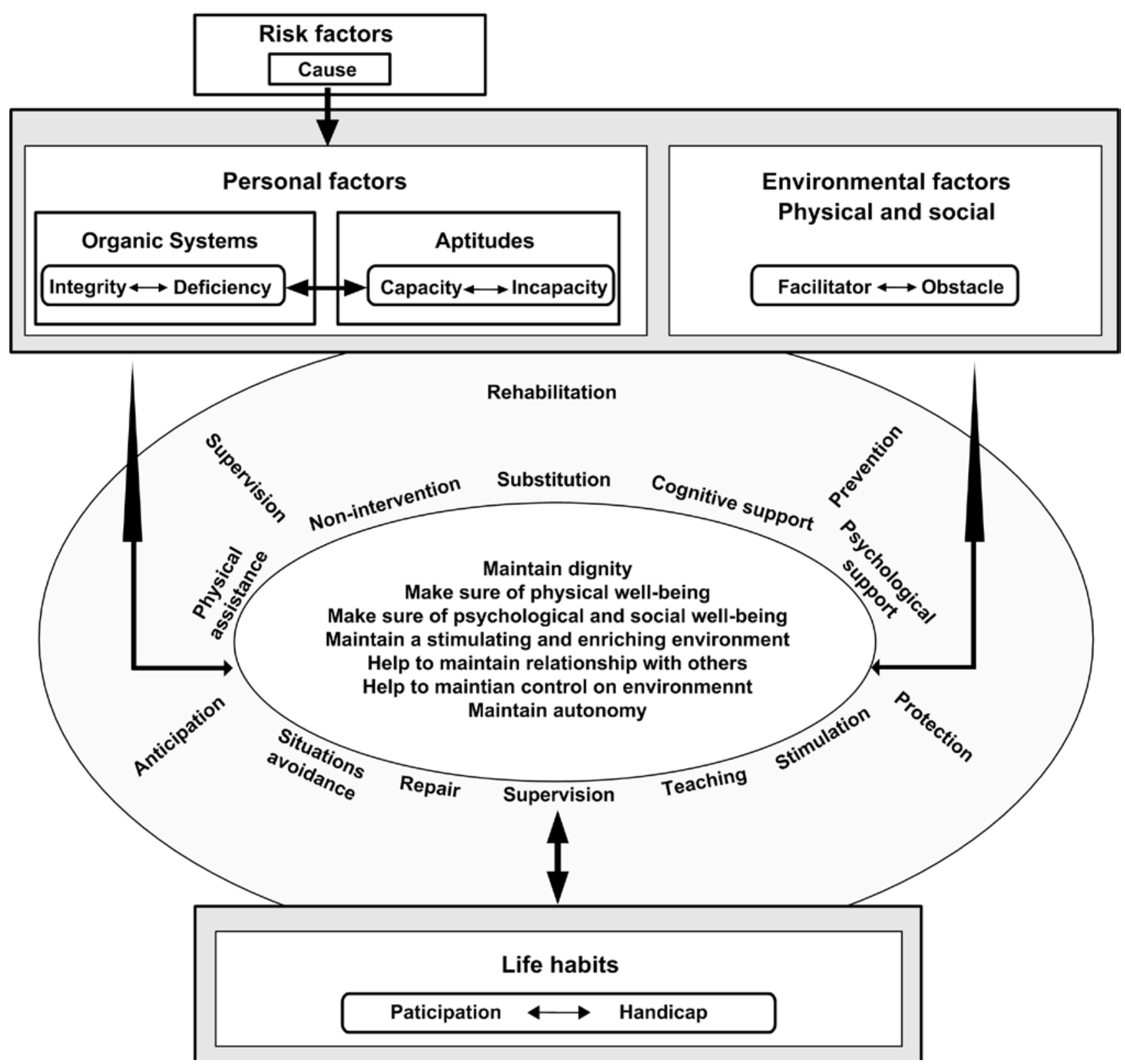

Figure 3: Type of help provided in optimizing participation in older adults who have cognitive deficits following a stroke.

\section{Discussion}

To our knowledge, this is the first study to explore the types of help provided by caregivers to optimize participation according to specific cognitive deficits following a stroke in older adults living at home. Our results showed that help varies according to factors related to the caregiver, such as his/her values and aims, the care receiver including the nature of his/her cognitive deficits, the dyad's relationship and the physical and social environment.

The DCP, Bower [6] and Vezina and Pelletier [7] models provide an interesting framework for this study aimed at understanding the help provided by caregivers in promoting participation. In fact, the help provided, modulated by the caregiver's objectives and values, appears to influence not only participation but also personal and environmental factors. The different kinds of help are not uniformly provided with all cognitive deficits, as already discussed. In addition, another study suggested that the kind of help varies according to the severity of the disease [11]. Our results show that the kind of help provided also varies according to the nature of the cerebral lesion, and more specifically of specific cognitive deficits. In fact, caregivers intervene mainly in the presence of executive deficits. Their interventions could contribute, in spite of the care receiver's executive deficits (inhibition), to good participation in daily activities and social roles in the first six months after returning home following a stroke.

Among the factors related to caregivers that influence the kind of help provided, when caregivers have a good understanding of the cause and manifestations of the cognitive deficits, they use the kinds of help that promote autonomy, such as teaching and cognitive support. 
Caregivers rarely intervene to optimize participation in the presence of perceptual deficits which they do not recognize, as compared to much more apparent cognitive deficits such as memory and language (expression) deficits. In fact, in our study, perceptual deficits and hemineglect detected by quantitative neuropsychological tests are rarely recognized and reported by caregivers in qualitative interviews.

Even if it was not one of our objectives to explore changes over time in the types of help provided in the first six months after discharge home, conducting three interviews with each caregiver helped deepen our understanding of the help provided in the different participation domains. Our qualitative results showed that sometimes cognitive deficits decrease over time and the help provided is modified. Conversely, other cognitive deficits not understood by the caregivers at the time of the first interview might be better understood by the following interviews and benefit from help provided by the caregiver. In addition, even if some deficits were not correctly identified by the caregivers, the interviewer was able to identify cognitive deficits described using other terminology or from behavioural manifestations in activities.

Furthermore, our study indicated that caregivers sometimes report functional impacts of cognitive deficits that were not detected by neuropsychological tests. In fact, there might be dissociation between the functional impact of cognitive deficits and results on neuropsychological tests [12]. Sometimes mild cognitive deficits are not recognized in neuropsychological tests but could have an impact on activities, as reported by caregivers. This is especially true of executive deficits that do not appear in short, structured tests but become apparent in spontaneous activities which are less structured and often last longer $[12,13]$.

Similarly to Bower's [6] results, our data show that the help provided is influenced by the caregiver's values and objectives. Caregivers of people who had a stroke enhance the value of autonomy, psychological well-being and security. Caregivers' objectives are to anticipate care receivers' needs, protect their identity, prevent abilities from deteriorating and supervise the formal services received [7]. In addition to those four objectives, our study with caregivers' of person who had a stroke shows that caregivers also pursue rehabilitation objectives.

A wider variety of types of help and also more extensive help is provided for social roles than for daily activities. Social roles are often cognitively more complex to accomplish for people with mild to moderate stokes than daily activities, which rely in part on preserved procedural capacities [13]. More specifically, the wider variety of help is applied to the leisure domain, which is the most affected domain after stroke [14]. Even with the help provided, few leisure activities are resumed after a stroke. However, without caregivers' help, leisure could be even more restricted. Similarly, like people who benefit from rehabilitation interventions for different health conditions, the study of Jette et al. [2] showed that social support positively influences the level of participation after returning to the community.

Our results show that environmental factors also influence the domains in which caregivers provide help in the presence of cognitive deficits. In fact, when family members or paid staff help with ADL which are essential for survival, caregivers have more time to promote social roles more related to self-actualization. Hence help from caregivers is often more effective when the family dynamic is good as they also have roles other than being a caregiver, such as worker, parent or spouse [15].
Our analysis of the caregivers' interviews indicated that the dyad's relationship influences some participation domains targeted by the caregiver. Those results confirm a study which found that the caregiver's in-depth knowledge of the care receiver could influence her/his role and that the dyad's relationship is a central element defining this role [16]. However, awareness has a great impact on the utilization of strategies [12]. Even if caregivers try to provide help, if the care receiver lacks awareness of his/her cognitive deficits, he/she would not use strategies. Future studies should follow changes over time in participation according to the kind of help provided by caregivers to people with cognitive deficits.

\section{Strengths and limitations}

The qualitative design was very useful in gaining an in-depth understanding of the types of help provided by caregivers according to specific cognitive deficits following a stroke. Qualitative methodology is especially helpful in studying the caregivers' role because it leaves the door open to discovering unanticipated aspects of the concept, especially in this case where the quantitative test, the Life- $\mathrm{H}$, does not distinguish between the kinds of help received. Attaining saturation allowed us to better understand differences in help provided according to different elements, including cognitive deficits.

The criterions of scientificity suggested by Laperriere [17] (auditability, credibility, transferability) were followed to meet scientific requirements. A social desirability bias could be present in the qualitative interviews even though the caregivers were not aware of the study objective. Nevertheless, the three interviews with each caregiver could have reduced this bias by establishing a relationship of trust with the interviewer (first author) and enhanced the validity of the information shared by the caregivers. Moreover, these three interviews helped to enrich our understanding of the different factors that influence the help provided. None of the participants dropped out the study.

Although recruitment took place in different institutions, we cannot assume that they are representative of all stroke caregivers. However, the rigor of the study allows transferability of the results to other caregivers who help persons who had a stroke. The relatively short duration of the study aimed to limit attrition but do not allow us to see if new kinds of help emerge later. Despite the study's limitations, the findings provide insight into the types of help provided by caregivers according to the nature of cognitive deficits following a stroke.

In conclusion, following a stroke, the help provided by caregivers is influenced by factors related to the care receiver, such as cognitive deficits, factors related to the caregiver, particularly his/her own values and objectives, and also by other factors related to their relationship and environment. The type of help provided by caregivers differs according to cognitive deficits and their understanding by the caregiver. Memory, executive and language deficits are more often understood than perceptual deficits or hemineglect. The deficits that are more understood receive more caregivers' help. Although all participation domains benefit from caregivers' help, social roles receive more help than daily activities. A better understanding of the relationship between cognitive deficits and the type of help provided is needed to optimize rehabilitation efforts. This study contributes to the knowledge in the domain of partnership between caregivers and health professionals. This better partnership could enhance participation of people who suffer from cognitive deficits following a stroke. Professionals could then identify the most efficient kind of help according to specific 
Citation: Viscogliosi C, Caron C, Desrosiers J, Belleville S (2013) Types of Help Provided by Caregivers Following a Stroke: Optimizing Participation in Daily Activities and Social Roles According to Cognitive Deficits. J Gerontol Geriat Res 2: 118. doi:10.4172/2167-7182.1000118

Page 9 of 9

cognitive deficits, with a view to working in partnership with family caregivers to optimize post-stroke participation in helping care receivers use their preserved abilities in real life situations. Caregivers also could explore the care receivers' perception of the impact of the help received on their participation.

\section{Acknowledgment}

We would like to express our deepest gratitude to Dr. Chantal Caron, researcher at the Research Center on Aging in Sherbrooke, Quebec (Canada), for her vital contribution to this study. Right up to her death in January 2009, she continued to work on and sustain this project in remarkable fashion. This research was supported by the Canadian Institutes of Health Research (CIHR), the Heart and Stroke Foundation (HSF), the Quebec Rehabilitation Research Network (REPAR) and the Quebec Network for Research on Aging (RQRV). The authors thank al participants who gave their time. They thank the institutions which provided access to the participants and for their assistance. They thank the BRAD group for allowing this complementary study. The authors also wish to thank Frances Gallagher specifically for her help with the mixed analysis, Melanie Couture for the co-coding and revision of the article, Jocelyn Parenteau for transcribing the tapes and Annick Bourget, Diane Durand, Eloise Gaudreau and Michelle Plante who collected the quantitative data.

\section{References}

1. Bouchard RW, Mackey A (2007) Accident vasculaire cérébral. In Arcand M, Hébert R (Eds.)., Précis pratique de gériatrie. Acton Vale, Québec: Edisem.

2. Jette AM, Keysor J, Coster W, Ni P, Haley S (2005) Beyond function: predicting participation in a rehabilitation cohort. Arch Phys Med Rehabil 86: 2087-2094.

3. Fougeyrollas P, Cloutier R, Bergeron H, Cote J, St-Michel G (1998) Classification québécoise Processus de Production du Handicap. Quebec: RIPPH.

4. Bhogal SK, Teasell RW, Foley NC, Speechley MR (2003) Community reintegration after stroke. Top Stroke Rehabil 10: 107-129.

5. Guberman N, Lavoie JP, Pépin J, Lauzon S, Montejo ME (2006) Formal service practitioners' views of family caregivers' responsibilities and difficulties. Can J Aging 25: 43-53.

6. Bowers BJ (1988) Family perceptions of care in a nursing home. Gerontologist 28: 361-368.

7. Vézina A, Pelletier D (2001) Du domicile au centre d'hébergement et de soins de longue durée: formes et sens de la participation des familles. Québec: Centre de recherche sur les services communautaires. Université Laval.

8. Viscogliosi C, Desrosiers J, Belleville S, Caron CD, Ska B, et al. (2011) Differences in participation according to specific cognitive deficits following a stroke. Appl Neuropsychol 18: 117-126.
9. Spruytte N, Van Audenhove C, Lammertyn F, Storms G (2002) The quality of the caregiving relationship in informal care for older adults with dementia and chronic psychiatric patients. Psychol Psychother 75: 295-311.

10. Miles MB, Huberman AM (2003) Analyse des données qualitatives. Bruxelles: De Boeck.

11. Grant JS, Glandon GL, Elliott TR, Giger JN, Weaver M (2004) Caregiving problems and feelings experienced by family caregivers of stroke survivors the first month after discharge. Int J Rehabil Res 27: 105-111.

12. Van der Linden M, Meulemans T, Seron X, Coyette F, Andrès P, et al. (2000) L'évaluation des fonctions exécutives. Marseille: SOLAL.

13. Cahn-Weiner DA, Malloy PF, Boyle PA, Marran M, Salloway S (2000) Prediction of functional status from neuropsychological tests in communitydwelling elderly individuals. Clin Neuropsychol 14: 187-195.

14. Desrosiers J, Bourbonnais D, Noreau L, Rochette A, Bravo G, et al. (2005) Participation after stroke compared to normal aging. J Rehabil Med 37: 353357.

15. Bakas T, Austin JK, Jessup SL, Williams LS, Oberst MT (2004) Time and difficulty of tasks provided by family caregivers of stroke survivors. J Neurosci Nurs 36: 95-106

16. Caron CD, Bowers BJ (2003) Deciding whether to continue, share, or relinquish caregiving: caregiver views. Qual Health Res 13: 1252-1271.

17. Laperrière A (1997) Les critères de scientificité des méthodes qualitatives Montréal: Gaétan Morin.

18. Wechsler D (1987). WMS-R Wechsler Memory Scale-Revised. New York: The Psychological Corporation Harcourt Brace Jovanovich, Inc.

19. Stroop JR (1935) Studies of interference in serial verbal reactions. J Exp Psychol 6: 643-661.

20. Mercier L, Hébert R, Gauthier L (1995) Motor free visual perceptual test: impact of vertical answer cards position on hemispatial visual neglect. OTJR 15: 223 236 .

21. Gauthier L, Dehaul F, Joannette $Y$ (1989) The bells test: A quantitative and qualitative test for visual neglect. Int J Clin Neuropsychol 11: 49-54.

22. Kaplan EF, Goodglass H, Weintraub S (1983) The Boston Naming Test $\left(2^{\text {nd }}\right.$ edn) Philadelphia: Lea \& Febiger.

23. De Renzi E, Faglioni P (1978) Normative data and screening power of a shortened version of the Token Test. Cortex 14: 41-49.

24. Dordain M, Nespoulous JL, Bourdeau M, Lecours AR (1983) Verbal abilities of normal adults submitting to an aphasia linguistic protocol. Acta Neurol Belg 83: 5-16. 